\title{
Comparing Cognitive Failures and Metacognitive Beliefs in Mild Traumatic Brain Injured Patients and Normal Controls in Kashan
}

\author{
Fatemeh Zargar ${ }^{1}$; Abolfazl Mohammadi ${ }^{2}$; Elham Shafiei ${ }^{3,{ }^{*}}$; Esmaeil Fakharian ${ }^{3}$ \\ ${ }^{1}$ Department of Clinical Psychology, Kashan University of Medical Sciences, Kashan, IR Iran \\ 2 Department of Psychiatry, Roozbeh Hospital, Tehran University of Medical Sciences,Tehran, IR Iran \\ ${ }^{3}$ Trauma Research Center, Kashan University of Medical Sciences, Kashan, IR Iran \\ *Corresponding author: Elham Shafiei, Trauma Research Center, Kashan University of Medical Sciences, Kashan, IR Iran. Tel/Fax: +98-3155540021, E-mail: e_shafiey59@yahoo.com
}

Received: June 5, 2014; Revised: October 15, 2014; Accepted: February 16, 2015

\begin{abstract}
Background: Head trauma is associated with multiple destructive cognitive symptoms and cognitive failure. Cognitive failures include problems with memory, attention and operation. Cognitive failures are considered as a process associated with metacognition.

Objectives: This study aimed to compare cognitive failures and metacognitive beliefs in mild Traumatic Brain Injured (TBI) patients and normal controls in Kashan.

Patients and Methods:The study was performed on 40 TBI patients referred to the Shahid Beheshti Hospital of Kashan city and 40 normal controls in Kashan. Traumatic brain injured patients and normal controls were selected by convenience sampling. Two groups filled out the demographic sheet, Cognitive Failures Questionnaire (CFQ) and Meta-Cognitions Questionnaire 30 (MCQ-30). The data were analyzed by the SPSS-19 software with multivariate analysis of variance.

Results: The results of this study showed that there were no significant differences between TBI and controls in total scores and subscales of $C F Q$ and $M C Q(F=0.801, P=0.61)$.

Conclusions: Based on these findings, it seems that mild brain injuries don't make significant metacognitive problems and cognitive failures.
\end{abstract}

Keywords: Cognition; Brain Injury; Memory

\section{Background}

Head trauma is a major and preventable problem in health systems. It is a major cause of disability and death in young people (1). Annually, about 1.4 million people in the United States are treated for head injury. Of these 235000 are hospitalized, 8000 people develop lifelong disabilities and 50000 people lose their lives (2).

In more than $50 \%-70 \%$ of accidents, the primary cause of death is Traumatic Brain Injury (TBI) (3). In a study from Kashan (one of the cities of Iran) the annual incidence of brain damage was reported to be 429 cases per 100000 individuals (4). Overall, estimates indicate that almost all patients after severe head injury, more than half after average injury and about $10 \%$ of patients after minor injury develop stable neurological and psychological complications (5). According to the fifth edition of Diagnostic and Statistical Manual of mental disorders (DSM-V), the two main groups of symptoms of head injury include destructive cognitive and behavioral symptoms (6). Cognitive destruction and cognitive failure can lead to impairment in cognitive tasks. In this case, the patient would not be able to complete cognitive tasks that they normally performed (7). Cognitive failures are cognitive blun- ders that the individual must have the capacity to do normally (8). These include problems with memory lapses, attention, and operation (7). Cognitive failures occur in many situations, yet in some situations can lead to disaster (9). Cognitive failures are from the factors that caused automobile and work-related accidents (10-12). Traumatic Brain Injury participants reported significantly greater scores by the Cognitive Failures Questionnaire (CFQ) (13). On the other hand, cognitive failures are considered as processes associated with metacognition (14). Metacognition is involved in assessment, monitoring and cognitive control (15). Metacognitive beliefs have two domains: first, positive beliefs about the advantages and benefits of engaging in special cognitive activities. Second, negative beliefs that are relevant to the uncontrollability and dangerousness of some thoughts and experiences. Believing that "having anxiety about the future helps me plan for my future," is an example of a positive metacognitive belief and the belief that "the inability to remember names, signs my poor memory" is an example of a negative metacognitive belief (16). There is a significant positive correlation between cognitive failures and metacognition.

Copyright (c) 2015, Kashan University of Medical Sciences. This is an open-access article distributed under the terms of the Creative Commons Attribution-NonCommercial 4.0 International License (http://creativecommons.org/licenses/by-nc/4.0/) which permits copy and redistribute the material just in noncommercial usages, provided the original work is properly cited. 
In a study conducted on a sample of 165 subjects aged 18 to 58 years, it was demonstrated that positive metacognitive beliefs decrease in people with cognitive failures. Among the metacognitive component, positive beliefs about worry, cognitive confidence and negative beliefs about the controllability of thoughts have a positive relationship with cognitive failures (14). Although researches have shown that serious brain injuries result in cognitive problems, yet limited research, on cognitive failures in patients with mild traumatic brain injury, has been conducted. In addition, metacognition as a new variable in cognition studies has been less studied in patients with brain injury.

\section{Objectives}

The aim of this study was to compare cognitive failures and metacognitive beliefs in mild TBI patients and normal controls in Kashan.

\section{Patients and Methods}

The population of this study comprised of all patients with mild head injury, who had been hospitalized at Shahid Beheshti Hospital of Kashan city from April 2013 to December 2014, as well as a group of normal controls from Kashan. Forty TBI patients and 40 normal controls were selected by convenience sampling. Inclusion criteria for the TBI group were having mild brain damage, Glasgow Coma Scale (GCS) score of $\geq 13$ and being between 18 and 70 years of age. Exclusion criteria in TBI group were moderate to severe brain damage, substance dependency and having a mental disorder. An inclusion criterion for the control group was being between 18 and 70 years old. Exclusion criteria for the control group were substance dependency and having a mental disorder. A clinical psychologist referred to the neurology section of the hospital and after ensuring the ability of patients to respond, they were provided with the questionnaires. If patients had difficulty in reading or understanding the questions, thorough explanations were provided. People in the control group were selected from hospital staff, and were matched in terms of demographic characteristics with the patient group. The two groups filled out the demographic sheet, Meta-Cognitions Questionnaire 30 (MCQ-30) and CFQ. Gender, age, education level, marital status, race and history of previous injury were recorded in the demographic sheet.

\subsection{Instruments}

Cognitive failures questionnaire was designed in the year 1982. This scale has 25 items answered based on a five-point Likert scale (from "never" to "always"). It has four components that include distractibility, memory lapses, blunders and forgetting people's names (7). Wallace (17) reported that the alpha coefficient of this questionnaire is 0.96 and its reliability is 0.51 . In an Iranian sample, the coefficient of internal consistency and testretest reliability (after one month), were 0.89 and 0.77 , respectively (18).

A Persian version (19) of MCQ-30 (20) was used in this study. This measure assesses individual differences in metacognitive beliefs, judgments and monitoring tendencies. It consists of five factors assessed by 30 items in total. These subscales were labeled Positive Beliefs about Worry (POS), Negative Beliefs about the Controllability of Thoughts and Corresponding Danger (NEG), Cognitive Confidence (CC), Need for Control (CC), and Cognitive Self-Consciousness (CSC). Respondents were asked to rate whether they "generally agreed" with the statements. The original MCQ (20) and its Persian version (19) possess good internal consistency and convergent validity, as well as acceptable test-retest reliability.

\subsection{Ethical Considerations}

This study was approved by the Research Ethics Committee of Kashan University of Medical Sciences (the project number 9211). Also, before the start of the study, informed consent was obtained from all participants. The participants were assured of the confidentiality of all their personal information.

\subsection{Data Analysis}

Data analysis including descriptive and inferential statistics was performed using the SPSS software, version 19.0. The scores of subscales and total score of MCQ, CFQ and socio-demographic characteristics were entered for analysis. To confirm symptomatic differences between the TBI and control groups, multivariate analysis of variance was performed comparing the groups on measures of subscales and total score of MCQ and CFQ.

\section{Results}

Table 1 summarizes demographic characteristics of the TBI and the control group. Table 2 provides the means and standard deviations in subscales and total scores of MCQ and CFQ for TBI and control groups. The Levine test confirmed the equality of variances in the two groups in all scales and total scores. There were significant differences between the two groups in all scales except memory lapses. Because age and education had significant correlations with some subscales of MCQ and CFQ, they were entered as covariate variables in the Multivariate Analysis of Covariance (MONCOVA) model. Multivariate tests such as Hotelling's Trace showed there were no significant differences between TBI and control groups in total scores and subscales of CFQ and MCQ $(F=0.801, P=0.61)$.

Comparison of TBI and the control group in total scores and subscales of CFQ and MCQ are provided in Table 3. The table shows that in none of the scales of the questionnaires there were significant differences between the two groups. 
Table 1. Distribution of the Demographic Characteristics of the Traumatic Brain Injury and the Control Group ${ }^{\text {a }}$

\begin{tabular}{lcc}
\hline Variables & TBI & Control \\
\hline Educational level & & \\
$\quad$ Illiterate & $3(7.5)$ & $5(12.5)$ \\
\hline Primary school & $7(17.5)$ & $4(10)$ \\
Junior school & $13(32.5)$ & $16(40)$ \\
$\quad$ Senior school & $16(40)$ & $10(25)$ \\
$\quad \geq$ Bachelor & $1(2.5)$ & $5(12.5)$ \\
Gender & & \\
$\quad$ Male & $30(75)$ & $30(75)$ \\
\hline Female & $10(25)$ & $10(25)$ \\
Race & & $37(92.5)$ \\
$\quad$ Iranian & $39(97.5)$ & $3(7.5)$ \\
\hline Other & $1(2.5)$ & $12(30)$ \\
\hline Marital status & & $28(70)$ \\
\hline Single & $11(27.5)$ & \\
$\quad$ Married & $29(72.5)$ & \\
\hline Values are presented as frequencies (percentages). &
\end{tabular}

Table 2. Means and Standard Deviations for Cognitive Failures Questionnaire and Meta-Cognitions Questionnaire 30 Subscales for the Traumatic Brain Injury and the Control Group

\begin{tabular}{lcccc}
\hline Variables & \multicolumn{2}{c}{ Mean } & \multicolumn{2}{c}{ Std. Deviation } \\
\cline { 2 - 5 } & Control & TBI & Control & TBI \\
\hline Positive beliefs about worry & 12.8093 & 14.3615 & 5.33824 & 5.08407 \\
Negative beliefs about & 14.7827 & 15.5573 & 2.96164 & 3.93535 \\
controllability & & & & \\
Cognitive confidence & 12.3816 & 14.3125 & 4.72971 & 4.91697 \\
Need for control & 15.9187 & 15.5965 & 4.05028 & 4.56157 \\
Cognitive self-consciousness & 16.9206 & 17.0250 & 3.66203 & 4.02866 \\
Total MCQ & 72.8129 & 76.8528 & 15.47470 & 19.03326 \\
Total CFQ & 41.7914 & 44.3998 & 9.59564 & 12.33132 \\
\hline Distraction & 15.7841 & 16.9040 & 3.93340 & 5.08190 \\
\hline Memory lapses & 11.2272 & 12.0084 & 2.72339 & 3.83172 \\
Blunders & 11.5130 & 11.7704 & 3.15695 & 3.32071 \\
\hline Forgetting people's names & 3.2670 & 3.7170 & 1.12786 & 1.40091 \\
\hline
\end{tabular}

Table 3. Comparison of Cognitive Failures Questionnaire and Meta-Cognitions Questionnaire 30 Scales for the Traumatic Brain Injury and Control Group

\begin{tabular}{lcccc}
\hline Dependent Variable & Mean Square & df & F & Sig. \\
\hline $\begin{array}{l}\text { Positive beliefs about } \\
\text { worry }\end{array}$ & 48.187 & 1 & 1.773 & 0.187 \\
$\begin{array}{l}\text { Negative beliefs about } \\
\text { the controllability }\end{array}$ & 12.000 & 1 & 0.989 & 0.323 \\
\hline $\begin{array}{l}\text { Cognitive confidence } \\
\text { Need for control }\end{array}$ & 74.562 & 1 & 3.204 & 0.077 \\
\hline $\begin{array}{l}\text { Cognitive self- } \\
\text { consciousness }\end{array}$ & 2.076 & 1 & 0.112 & 0.739 \\
\hline $\begin{array}{l}\text { Total MCQ } \\
\text { Total CFQ }\end{array}$ & .218 & 1 & 0.015 & 0.904 \\
\hline $\begin{array}{l}\text { Distraction } \\
\text { Memory lapses }\end{array}$ & 326.418 & 1 & 1.085 & 0.301 \\
\hline Blunders & 136.078 & 1 & 1.115 & 0.294 \\
\hline $\begin{array}{l}\text { Forgetting people's } \\
\text { names }\end{array}$ & 25.083 & 1 & 1.215 & 0.274 \\
\hline
\end{tabular}

\section{Discussion}

Cognitive failures are variables that cause accidents and workplace mishaps. Cognitive failures include problems with memory, attention and operation $(8,12,17)$. On the other hand, there is a significant positive correlation between cognitive failures and metacognition. The self-reporting of cognitive failures is a process that is related to metacognitive beliefs, ability to monitor and control cognitive activities (21). Kashan is a natural disaster-prone city in Iran, especially in terms of road accidents. The aim of the present study was to compare cognitive failures and metacognitive beliefs in TBI patients and normal controls in Kashan.

This study indicated no significant difference between the two groups in cognitive failures and metacognitive beliefs. The results of this study are inconsistent with the findings of other studies that showed significant differences in cognitive failures and metacognitive beliefs in TBI and normal controls (13-16). In these studies moderate TBI patients were studied. It seems that there is a direct correlation between the severity of the injury and cognitive deficits, and metacognitive beliefs (22). DSM stipulates that about $10 \%$ of patients, after minor injury, develop stable neurological and psychological complications (5). Given that in the present study only patients with mild TBI were studied, it seems that one of the reasons for the lack of significant difference between the two groups is due to the mentioned point. However, a look at the scale scores of CFQ and MCQ in the two groups, showed higher scores for the TBI group when compared to the control group. Some studies did not report a significant relationship between the components of metacognition such as cognitive awareness and brain injury $(23,24)$. In fact, in this study, no significant relationship was found between the severity of brain injury and cognitive awareness (24).

Most TBI participants in our study had automobile accidents yet other disasters such as occupational events were included. Other studies reported on cognitive failures as a result of automobile and work-related accidents (10-12). However, some other factors such as drugs and alcohol use, driving training and experience, familiarity with vehicle and environment, fatigue, perception-reaction time, response to the unexpected, risky behaviors, stress and mental disorders affected the prevalence of accidents. The Kashan Freeway is an important intermediate in the path of crowded cities such as Tehran, Isfahan and Qom and the above factors can have an effect on the occurrence of road accidents in this area.

This study showed that there is no significant difference between the TBI and the control group in cognitive failures and metacognitive beliefs. The limitation of this study was the use of convenient sampling. Since TBI patients were selected from referred patients to the Shahid Beheshti Hospital, generalizing the results to other TBI groups should be done with caution. 


\section{Acknowledgements}

The authors would like to acknowledge the staff of the emergency unit of Kashan Shahid Beheshti Hospital for their assistance in gathering data.

\section{Authors' Contributions}

Fatemeh Zargar developed the idea, designed and implemented the study. Elham Shafiei collected the data. Esmaeil Fakharian supervised the study.

\section{Funding/Support}

This study was supported by the Deputy of Research of Kashan University of Medical Sciences (Grant no: 9211).

\section{References}

1. Jennett B. Epidemiology of head injury. Arch Dis Child. 1998;78(5):403-6.

2. SmeltzerSC,BaRB.Textbookofmedical-surgicalnursing.Philadelphia: Lippincott Williams \& Wilkins; 2008.

3. Ratan SK, Pandey RM, Kulsreshtha R, Ratan J. Risk factors for mortality within first 24 hours of head injury. Indian J Pediatr. 2002;69(7):573-7.

4. Farzandipour M, Ghattan H, Mazrouei L, Nejati M, Aghabagheri T. Epidemiological study of traumatic patients referred to neghavi hospital of kashan. J Kermanshah Uni Med Sci. 2007;11(1):58-66.

5. Sadock E, Auerbach SM, Rybarczyk B, Aggarwal A. Evaluation of integrated psychological services in a university-based primary care clinic. J Clin Psychol Med Settings. 2014;21(1):19-32.

6. psychiatryonline. American Psychiatric Association. Arlington: VA:American Psychiatric Publishing; 2013. Diagnostic and Statistical Manual of Mental Disorders (Fifth ed.)

7. Bridger RS, Johnsen SA, Brasher K. Psychometric properties of the Cognitive Failures Questionnaire. Ergonomics. 2013;56(10):1515-24.

8. Allahyari T, Rangi NH, Khalkhali H, Khosravi Y. Occupational cognitive failures and safety performance in the workplace. Int J Occup SafErgon. 2014;20(1):175-80.

9. Simpson SA, Wadsworth EJ, Moss SC, Smith AP. Minor injuries, cognitive failures and accidents at work: incidence and associated features. Occup Med (Lond). 2005;55(2):99-108.

10. Day AJ, Brasher K, Bridger RS. Accident proneness revisited: the role of psychological stress and cognitive failure. Accid Anal Prev. 2012;49:532-5.

11. Wadsworth EJ, Simpson SA, Moss SC, Smith AP. The Bristol Stress and Health Study: accidents, minor injuries and cognitive failures at work. Occup Med (Lond). 2003;53(6):392-7.

12. Wickens CM, Toplak ME, Wiesenthal DL. Cognitive failures as predictors of driving errors, lapses, and violations. Accid Anal Prev. 2008;40(3):1223-33.

13. Hart T, Whyte J, Kim J, Vaccaro M. Executive function and self-awareness of "real-world" behavior and attention deficits following traumatic brain injury. J Head Trauma Rehabil. 2005;20(4):333-47.

14. Righi S, Mecacci L, Viggiano MP. Anxiety, cognitive self-evaluation and performance: ERP correlates. J Anxiety Disord. 2009;23(8):1132-8.

15. Lehto JE, Elorinne E. Gambling as an executive function task. App Neuropsychol.2003;10(4):234-8.

16. Wells A, Welford M, King P, Papageorgiou C, Wisely J, Mendel E. A pilot randomized trial of metacognitive therapy vs applied relaxation in the treatment of adults with generalized anxiety disorder. Behav Res Ther. 2010;48(5):429-34.

17. Wallace JC, Vodanovich SJ. Workplace safety performance: conscientiousness, cognitive failure, and their interaction. J Occup Health Psychol. 2003;8(4):316-27.

18. Abolghasemi A. . Investigate the relationship between cognitive beliefs and religious cognition in middle and Salmnda failures.. Ardabil: University of Mohaghegh Ardabil; 2008.

19. Shirinzadeh Dastgiri S, Goodarzi MA, Rahimi C, Naziri G. Study of factor structure, validity and reliability of metacognitions questionnaire-30. J Psychology. 2009;12:445-61.

20. Wells A, Cartwright-Hatton S. A short form of the metacognitions questionnaire: properties of the MCQ-30. Behav Res Ther. 2004;42(4):385-96.

21. Esbjorn BH, Lonfeldt NN, Nielsen SK, Reinholdt-Dunne ML, Som hovd MJ, Cartwright-Hatton S. Meta-worry, worry, and anxiety in children and adolescents: relationships and interactions. J Clin Child Adolesc Psychol. 2015;44(1):145-56.

22. Hall RC, Hall RC, Chapman MJ. Definition, diagnosis, and forensic implications of postconcussional syndrome. Psychosomatics. 2005;46(3):195-202.

23. Prigatano GP, Altman IM. Impaired awareness of behavioral limitations after traumatic brain injury. Arch Phys Med Rehabil. 1990;71(13):1058-64.

24. Allen CC, Ruff RM. Self-rating versus neuropsychological performance of moderate versus severe head-injured patients. Brain Inj. 1990;4(1):7-17. 